\title{
sobre Arcana Imperii. Tratado metafísico-político. La comunidad de los espectros III, de Fabián Ludueña Romandini. Buenos Aires: Miñoy Dávila, 2018.
}

\author{
RAFAEL ARCE Universidad Nacional del Litoral - CONICET, Argentina / rafael.arce@gmail.com
}

En la universidad de las antaño llamadas ciencias humanas, tan castigada hoy por el desdén y la demanda de productividad, hay (por lo menos) dos clases de pensadores: los que realizan un trabajo de hormiga, para el museo, conscientes (o no) de que nuestra tarea es hoy meramente paleontológica (contribuyen, por lo tanto, y así prueban su «utilidad», al patrimonio cultural de nuestras antaño llamadas naciones); son los recogedores de los residuos de la historia y quienes ordenan la biblioteca del saber universal desconectado ya de toda vida o mundo (dando la razón, en suma, a la tentativa hegeliana); y los que, por el contrario, inquietan la textualidad occidental (y oriental) para pensar problemas acuciantes: son quienes, lejos de perorar a favor de la «importancia» de las humanidades, ponen en juego los saberes para enfrentarse con un mundo que está en trance de transformarse de modo irreversible.

Fabián Ludueña Romandini, como si viviera en Francia o en Alemania, y no en Argentina, viene proponiendo desde hace algunos años una tentativa cuya envergadura y ambición están acorde con la magnitud de los problemas con los que se enfrenta. Arcana Imperii. Tratado metafísicopolítico. La comunidad de los espectros III constituye la desmesurada (tan meticulosa y sobria como, paradójicamente, desesperada) tentativa de empezar siquiera a pensar la mutación a escala planetaria (y cósmica) que se está produciendo en nuestras sociedades «transhumanistas». Su perspectiva es en sí misma provocadora, a contracorriente del consenso posmetafísico: en una suerte de retorno a Platón, pero habiendo pasado por la arqueología foucaultiana, la desconstrucción derridiana y los matemas lacanianos, Ludueña afirma la necesidad de volver a hablar de metafísica (aunque se trate paradójicamente de una metafísica de la ausencia o parametafísica), es decir, de restaurar (palabra que él no usa y que suena sospechosa) un pensamiento de lo invisible, en un mundo en el que el sentido común materialista convive contradictoriamente con la desmaterialización de la cuántica y del universo virtual. Coherente con este ir a contramano de las tendencias hegemónicas de todos los "post» (de los que el filósofo desconfía), ya en la introducción de su La comunidad de los espectros II. Principios de espectrología, Ludueña comenzaba nada menos que por la cuestión del estatuto de la verdad, otra de esas palabras caídas bajo sospecha.

\footnotetext{
Para citar este artículo: Arce, Rafael (2019). Sobre: Arcana Imperii. Tratado metafísico-político. La comunidad de los espectros III, de Fabián Ludueña Romandini. El taco en la brea, 9 (diciembre-mayo), 116-118. Santa Fe, Argentina: UNL. DOI: 10.14409/tb.viig.8194
} 
Si hay una tesis central del libro (tal vez haya muchas y ninguna central), estribaría en un diagnóstico: la caducidad de todas las categorías con las que Homo se pensó como animal político, desde la polis griega hasta las revoluciones modernas pasando por el episodio nodal de la Revolución Francesa. Este diagnóstico se demuestra por la vía de la arqueología de algunos conceptos claves de las teorías política y económica modernas (auctoritas, potestas, soberanía, revolución, sociedad de control, seguridad, capitalismo, neoliberalismo, Estado). Esta genealogía otorga al recorrido un vaivén entre la historia humana (antigua, medieval, moderna) y nuestra contemporaneidad, siempre yendo más atrás, hacia lo que permanece impensado, y más adelante, hacia lo que se puede avizorar (con tesis fuertes y sugerentes como la de una inminencia amesiánica). La erudición de Ludueña no es exhibicionista sino que está al servicio de su operatividad: los pensadores del pasado no son reliquias para la historia de la filosofía, sino que podemos pensar con ellos, aún, los fenómenos más impactantes de nuestro tiempo y sus no del todo ceñidas consecuencias políticas y económicas: la teoría cuántica, la Singularidad, la teoría algorítmica, la teoría de la información, la cosmología. Los Póstumos, como los llama Ludueña (es decir, los «humanos» después del desmantelamiento de la Modernidad Humanista), deben forjar las nuevas herramientas teóricas que posibiliten pensar la configuración político-económica que todavía se encuentra en agencia.

Ahora bien, esta arqueología se incluye en una más vasta "cosmogonía». Desde la primera entrega de su trilogía (La comunidad de los espectros I. Antropotecnia), Ludueña sugiere volver a esa conexión propia de los antiguos, quienes pensaron el mundo no limitado por Gea, sino como un punto del Cosmos. La desconexión moderna de la filosofía de la cosmogonía (en parte debida a la secularización, a la emergencia de la ciencia y del Sujeto) parece quedar obsoleta en el mundo contemporáneo en la medida en que la exploración del espacio sideral, la amenaza del desastre ecológico, la posibilidad de pensar un modo de vida orgánico que prescinda del carbono que propone el proyecto de la IA y el vago programa de una vida humana (o transhumana) fuera del planeta, vuelven a depositar la atención en lo extra-humano y extra-terrestre como horizonte de infinitud: «En cierta forma, se está produciendo, bajo nuestros pies, un fenómeno inverso al de la secularización: los conceptos políticos no se trasladan de la esfera divina a la humana sino que, al contrario, esas nociones vuelven a su raíz inhumana de origen, salvo que ahora se pretenden vinculadas a entidades algorítmicas que en ningún caso responden a la metafísica de lo inefable y del milagro, propia de la teología política occidental». No se trata ni del fin de la Historia ni de su optimista (o nihilista: «La nada no es otra cosa que el nombre secreto de la forclusión pneumática, esto es, la ontología de lo invisible») continuación, sino de repensar la Historia Universal como prehistoria de un nuevo eón en el que el tiempo de los hombres y el tiempo del cosmos replanteen los términos de sus relaciones, y también los de su mutua amenaza.

¿Cuáles son los arcanos del Imperio Humano? Ya no ocultos ni por la ininteligibilidad hermenéutica ni por los secretos de Estado, los arcanos son, como la carta de Poe, los secretos de la política mejor guardados por su visibilidad. Un ejemplo (aunque no se trate de un ejemplo de nada sino de la cosa en sí): la autoridad. Ludueña propone una arqueología del concepto y considera su inflexión posterior a la Revolución Francesa: la Restauración ya vislumbraba que la antigua auctoritas sería alguna vez prerrogativa de la opinión. En un tiempo como el nuestro, en el que la construcción de la opinión pública implica el destino político económico de un considerable lapso, la autoridad que era del pueblo ahora lo es de la doxa. Así, lo que parece en principio un análisis abstracto y quizás opaco de nociones filosóficas complejas, muy pronto revela toda su contemporaneidad: «Si la opinión se transforma en la surgente del poder, la política misma sufre un ocaso definitivo: la 
soberanía se reduce entonces, a su vez, a una servidumbre de la opinión masificada y a un intento por domesticar sus flujos mediante el gobierno de los medios de su transmisión. En un contexto semejante, conceptos como «república» o «democracia» alcanzan el más alto grado de opacidad pues no son más que otros elementos que integran la amalgama informe de la doxa mundial».

Ludueña tiene también su propia polémica con su maestro Agamben (y en menor medida con Foucault) por lo que, a pesar de sus presupuestos, Arcana Imperii toca como por tangentes problemas «actuales» como la vida, la sexualidad, la corporalidad. Lo hace, con la perspicacia derridiana de leer lo i-leído, provocativamente desarmando algunos lugares comunes acerca de la filosofía platónica (Platón: siempre superior a sus exégetas), volviendo a discutir las relaciones entre la carne y el alma, pivoteando sobre la asediada y tan difícil noción de psyché, proponiendo el concepto de sustrato deseante para interrogar las sexualidad griega como constitutiva, en sus arcanos (en el sentido de misterios y de secretos), de la política y la economía de la Ciudad. No contento con esto, vuelve sobre la lectura lacaniana de Sade, para interrogar esta misma relación siempre conflictiva (el deseo y la Ley, el cuerpo y la Ciudad, el individuo y la comunidad, la destrucción y la conservación) en el episodio de la Revolución y sus antecedentes en la moral kantiana como una tentativa visionaria de conjurar el orden de la ley humana con el orden de las leyes de la naturaleza (newtoniana). Es decir, que esta propuesta de pensar una metafísica posdesconstructiva (noción que Derrida habría rechazado como contrasentido) implica una ontología de lo invisible, pero no un espiritualismo, si se entiende que un espiritualismo conlleva el olvido o represión del cuerpo: «el Espíritu solo puede manifestarse en las propiedades adjudicadas a la carne y la carne sólo puede conocer su naturaleza material al aprehender que la misma está atravesada por una hendidura inmaterial que la habita y que, en su momento teológico-político, tuvo el nombre de pneuma». Los espectros de Ludueña, lo forcluido en la constitución teológico-política de Occidente, no son entes espirituales, sino lo que asedia tanto la filía griega como el puritanismo revolucionario y, en nuestros días, la frigidez y la indolencia en un universo virtual saturado de visibilidad, en donde el deseo, y no su objeto, es lo que se ha vuelto imposible (y donde lo que se reprime, curiosamente, y de nuevo Platón es evocado, es nada menos que el amor). Los espectros son los que suplician el cuerpo (al que nuestra era le proporciona confort y entretenimiento) y los que encarnan el dolor del alma (a la que nuestra era le suministra psicofármacos y seminarios de autoayuda, laica o evangelista).

Aunque Arcana Imperii podría pertenecer a la tradición de la escatología, ni puede reducirse a un pesimismo nihilista ni tampoco adscribirse a una propuesta optimista respecto de una comunidad por venir. Es tal vez un criptograma desencantado que se toma en serio la finitud y cuya gélida desesperanza se mide a la altura del horizonte de nuestra extinción. La tentativa desborda el diagnóstico, aunque solo la lectura de la trilogía completa reponga la conjetura ludueñana acerca de su filosofía del Outside. Sin esperanza, ¿cómo transformar la desesperación en fuerza política? ¿Cómo volver a pensar la política, insistir en ella, cuando pareciera que su tiempo ha llegado a su fin? No renunciar a la política, pero volver a pensar su componente constitutivo extra-humano (que Bataille llamaría sagrado) sin volver a la ontoteología de los transhumanistas pero sin renunciar tampoco a la potencia de lo que puede afirmarse cuando se asume, no ya la muerte, sino la desaparición misma de las nociones de muerte y vida, y no de vida y muerte humanas sino de vida y muerte a secas. Pensar ese impensable sería pensar el Afuera. ¿Y cómo sería una política del Afuera? La clave no estaría afuera (con minúscula), ni en el futuro, sino que sería el definitivo arcano, abandonado como runa en los despojos del Tiempo. 